\title{
Estudo de caso sobre diversidade e abundância de epífitas sobre forófitos de borda de fragmento do parque Witeck, Novo Cabrais - RS
}

\author{
Case study on diversity and abundance of epiphos on Witeck park fragmenting forophytes, \\ Novo Cabrais - RS
}

\author{
Jaqueline De Bortoli \\ Jonas Bernardes Bica \\ Deise Juliana Beckel Hendges \\ Emeli Lappe \\ Marcela Bruxel \\ Noeli Juarez Ferla \\ Claudete Rempel
}

Universidade do Vale do Taquari- UNIVATES - Lajeado - Rio Grande do Sul - Brasil

\section{Resumo}

As epífitas atuam nos processos de manutenção dos ecossistemas através do seu modo de vida, elas têm vantagens no acesso à luz solar e facilidade em espalhar suas sementes pelo vento. $O$ estudo teve por objetivo verificar a influência de fatores físicos sobre a diversidade e a abundância de epífitas sobre forófitos lenhosos de uma borda de um fragmento do Parque Witeck/Novo Cabrais-RS. Observou-se 10 forófitos e utilizou-se quadrante $(45 \times 45)$ para verificar a distribuição espacial em dois estratos, estratificação vertical e horizontal, temperatura e umidade. Em todos os forófitos estudados foram encontradas briófitas, criptógamas vasculares e líquens, com menor predominância deste último. Na área de estudo não foram encontradas diferenças estatísticas significativas na abundância e diversidade de epífitas sobre os forófitos analisados comparando com os fatores abióticos analisados.

\section{Abstract}

Epiphytes operate in ecosystems maintenance processes through their way of life, they have advantages in access to sunlight and ease in spreading their seeds in the wind. The study aimed to verify the influence of physical factors on the diversity and abundance of epiphytes on woody phorophytes an edge of a fragment of Witeck Park/Novo Cabrais - RS. 10 phorophytes observed and used quadrant $(45 \times 45)$ to check the spatial distribution in two layers, vertical and horizontal stratification, temperature and humidity. In all studied phorophytes found bryophytes, vascular cryptogams and lichens, with lower prevalence of the latter. In the study area were no statistically significant differences in the abundance and diversity of epiphytes on phorophytes analyzed comparing with the abiotic factors analyzed.

\section{Palavras-chave}

Briófitas. Criptógamas. Vasculares. Líquens.

\section{Keywords}

Bryophytes. Phorophytes. Cryptogamae Vascular. Lichens. 


\section{Introdução}

O Parque Witeck localiza-se ao longo da BR-153, no km 350, no município de Novo Cabrais/Rio Grande do Sul. Foi idealizado pelo médico ambientalista Acido Witeck, que no ano de 1962 adquiriu uma área de terras que se encontrava degradada em razão da criação extensiva de gado, queimadas e desmatamentos de reservas nativas da região. A partir de 1966, numa área de 10 hectares, foram plantadas algumas árvores e criou-se o primeiro reservatório de água que deu origem ao que hoje constitui o Lago Encantado (Parque Witeck, 2011).

Em 1967 iniciou-se o tratamento paisagístico da área e no ano de 1976 foram plantadas as primeiras coníferas originárias da Ásia, Europa, Oceania e América do Norte. Em 1977 destinaram-se mais 20 hectares ao que viria a ser o Parque Witeck e foram constituídas as primeiras ilhas temáticas, de acordo com as características das plantas (nativas da região, caducifólia, coníferas, palmeiras). Em 1991 a área do Parque passou a ter 70 hectares, o que se tem até os dias atuais.

O conhecimento da área faz-se através de trilhas demarcadas ao longo dos caminhos que são interligados aos diversos ambientes temáticos: Recanto da Paz, Europeu, das Caducas e dos lagos: Encantado, Mágico, da Paz e Grande Espelho do Céu, entre outros. A morfologia do terreno, os recursos hídricos e a ação antrópica são elementos que constituem a atual paisagem do Parque. Além da flora bastante diversificada onde se incluem espécies nativas e uma grande variedade de exóticas, observa-se ainda a ocorrência de plantas epífitas.

Denomina-se epifitismo a relação harmônica entre plantas que se desenvolvem sobre outras sem prejudicá-las, utilizando-as apenas como substrato para fixação. As epífitas encontram-se diretamente sobre o tronco, galhos, pedras, ramos ou sobre as folhas das árvores, sendo as plantas hospedeiras denominadas de forófitos (Dislich e Mantovani, 1998).

As epífitas representam importante contribuição à diversidade biológica das florestas em termos de riqueza de espécies e biomassa (Gentry e Dodson, 1987). Em uma mesma árvore, diferentes micro-habitats são formados e modificados ao longo do tempo, desde a base até a copa das árvores, permitindo com que um grande número de espécies possa ocupar esses substratos de acordo com suas necessidades ecofisiológicas (Benzing, 1990).

Através do seu modo de vida, essas plantas têm vantagens como: o acesso à luz solar e a facilidade em espalhar suas sementes pelo vento. Este grupo de plantas proporciona recursos alimentares como frutos, néctar, pólen, material para a construção de ninhos e água, além de microambientes especializados para a fauna, constituídos por uma infinidade de organismos voadores e arborícolas (Benzing, 1990).

Devido às suas funções fisiológicas e nutricionais, as epífitas fornecem subsídios importantes sobre a interferência antrópica no ambiente, sendo essenciais para o manejo adequado dos ecossistemas (Gonçalves e Waechter, 2003). As epífitas também funcionam como bioindicadores do estádio sucessional da floresta, tendo em vista que comunidades em fases secundárias apresentam menor densidade e diversidade epifítica do que comunidades primárias (Rogalski e Zanin, 2003).

Este estudo teve como objetivo verificar a influência de fatores físicos sobre a diversidade e a abundância de epífitas sobre forófitos lenhosos de uma borda de um fragmento de Floresta Estacional Decidual.

\section{Material e métodos}

\section{Área de estudo}

O presente estudo foi desenvolvido no parque particular da família Witeck, situado no município Novo Cabrais, localizado na região Central do Estado do Rio Grande do Sul (2947'11,03"S/5258'4,26"W - Datum WSG84) (Fig. 1). É o maior parque privado da América 
Latina, com espécies de plantas de diversos países do mundo. O local de coleta dos dados está

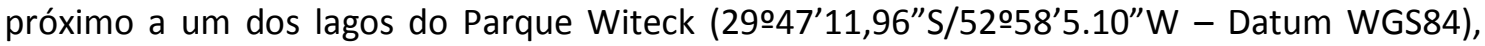
junto ao Recanto do Coração.

Figura 1: Localização do Município de Novos Cabrais no Estado do Rio Grande do Sul/BR e imagem do local de estudo (Parque Witek).

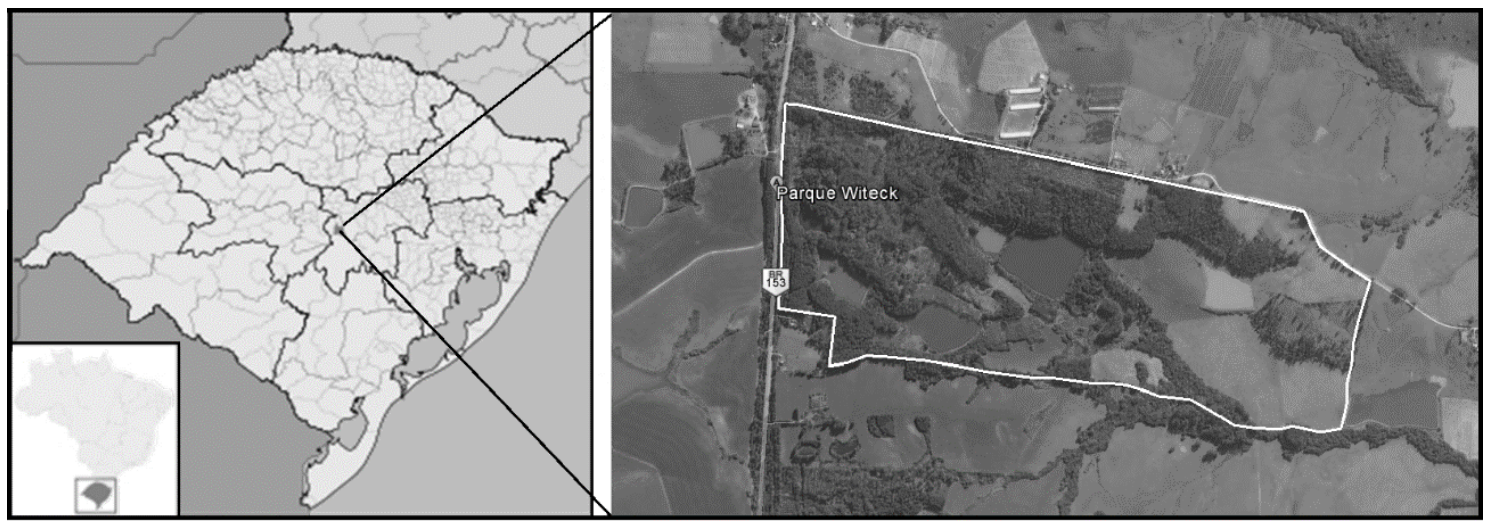

Fonte: Os autores. Adaptado de Google Earth 2014 - data da imagem 15/08/2013.

O parque está inserido no Bioma Mata Atlântica, dentro da fitorregião paisagística Floresta Estacional Decidual. Esse tipo de floresta caracteriza-se por apresentar duas estações climáticas marcadamente distintas durante o ano. A zona tropical é caracterizada por apresentar uma estação chuvosa seguida de período seco e na zona subtropical, sem período seco, porém, com inverno frio, temperaturas médias mensais menores ou iguais a 15드 (IBGE, 2012). Sua estrutura é representada por um estrato arbóreo contínuo de altura não superando 20 metros. A etimologia de seu nome é dado devido ao aspecto fisionômico marcado pela queda da folhagem de mais de $60 \%$ das espécies da cobertura arbórea superior (Leite, 1994; Marchiori, 2002).

\section{Coleta de dados}

A coleta de dados deste estudo foi realizada no mês de maio, no turno da tarde, com sol entre nuvens. Foram amostradas todas as epífitas identificadas em um fragmento de borda, em 10 forófitos, escolhidos aleatoriamente no fragmento, estratificados em dois níveis no substrato: até $2 \mathrm{~m}$ e acima de $2 \mathrm{~m}$. Para fins de classificação dos espécimes epífitos considerados neste estudo, optou-se por padronizar e classificar os grupos em morfoespécies: líquens, briófitas e criptógamos vasculares. A distribuição de morfoespécies foi observada através do método de quadrantes centrados (Kersten e Waechter, 2011). Foram observadas ainda as preferências de desenvolvimento, em relação às faces Norte e Sul, registrando sua distribuição espacial, estratificação vertical e horizontal. Verificou-se também a temperatura e a umidade em cada face dos forófitos observados.

Os dados de temperatura e umidade foram tomados com auxílio de um termo higrômetro, obedecendo o tempo de estabilização de 1 minuto, foram anotados os valores resultantes nos estratos abaixo e acima de $2 \mathrm{~m}$. Para quantificar o percentual de ocorrência de epífitas nos forófitos foi utilizando um quadrante centrado de $45 \mathrm{~cm} \times 45 \mathrm{~cm}$ (Fig. 2), realizando-se uma amostragem para cada parcela. Para a análise estatística utilizou-se o teste não-paramétrico de Kruskal-Wallis (Kruskal e Wallis, 1952).

Figura 2: Quadrante utilizado na amostragem. 


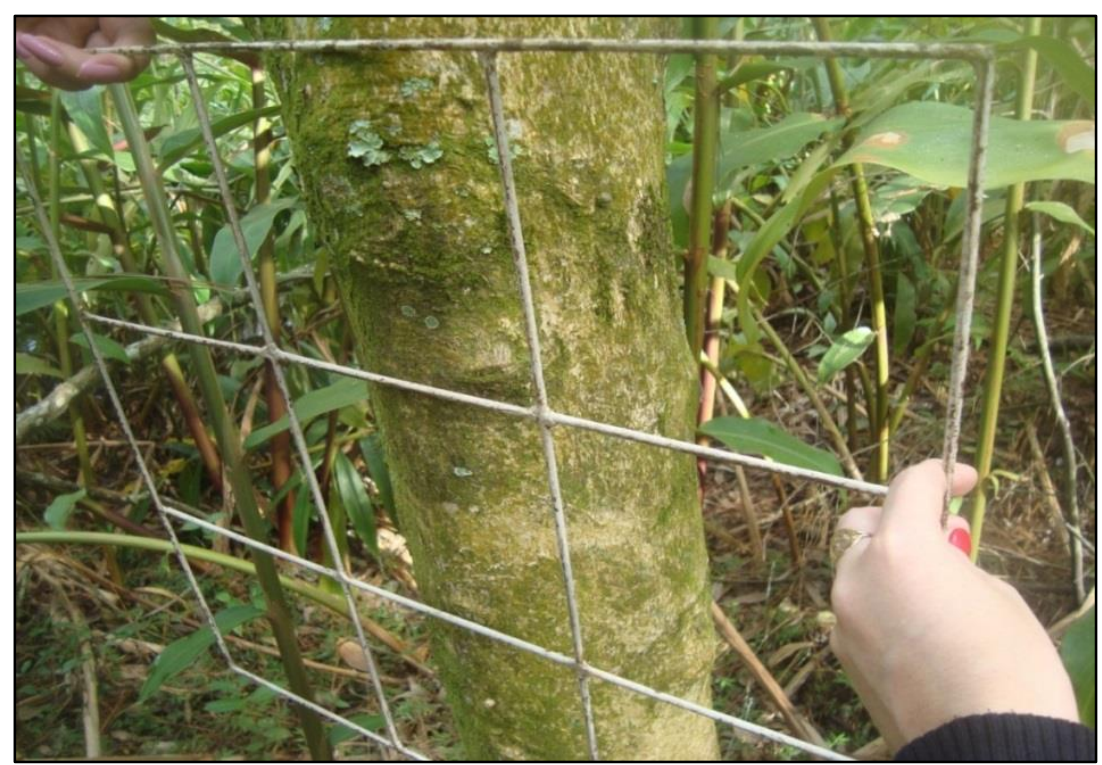

Fonte: Os autores.

\section{Resultados e discussões}

No levantamento da área de borda estudada observou-se 10 forófitos, todos apresentaram, pelo menos, alguma espécie de epífita, registrando-se a presença de três grupos: líquens, briófitas e criptógamas vasculares (Tabela. 1).

Tabela 1: Número de quadrantes com epífitas na área amostral, ocorrentes em cada parcela.

\begin{tabular}{|c|c|c|c|c|c|c|}
\hline \multirow[t]{2}{*}{ Forófito } & \multirow{2}{*}{$\begin{array}{l}\text { Diâmetro } \\
\text { do forófito } \\
\text { (cm) }\end{array}$} & \multirow[t]{2}{*}{ Epífitas } & \multicolumn{2}{|c|}{$\begin{array}{l}\text { № de quadrantes } \\
\text { Metade Inferior do } \\
\text { Tronco (até } 2 \mathrm{~m} \text { ) }\end{array}$} & \multicolumn{2}{|c|}{$\begin{array}{c}\text { № de quadrantes } \\
\text { Metade Superior } \\
\text { do Tronco (acima } \\
\text { de } 2 \mathrm{~m} \text { ) }\end{array}$} \\
\hline & & & Face Norte & Face Sul & $\begin{array}{l}\text { Face } \\
\text { Norte }\end{array}$ & Face Sul \\
\hline \multirow{3}{*}{1} & \multirow{3}{*}{23} & Líquens & 1 & 2 & 0 & 2 \\
\hline & & Briófitas & 3 & 3 & 3 & 1 \\
\hline & & Criptógamas vasculares & 0 & 2 & 3 & 2 \\
\hline \multirow{3}{*}{2} & \multirow{3}{*}{14} & Líquens & 3 & 3 & 0 & 3 \\
\hline & & Briófitas & 3 & 3 & 3 & 3 \\
\hline & & Criptógamas vasculares & 1 & 3 & 3 & 3 \\
\hline \multirow{3}{*}{3} & \multirow{3}{*}{47} & Líquens & 0 & 0 & 0 & 0 \\
\hline & & Briófitas & 3 & 0 & 3 & 0 \\
\hline & & Criptógamas vasculares & 3 & 0 & 3 & 0 \\
\hline \multirow{3}{*}{4} & \multirow{3}{*}{110} & Líquens & 3 & 0 & 2 & 2 \\
\hline & & Briófitas & 3 & 2 & 1 & 2 \\
\hline & & Criptógamas vasculares & 3 & 0 & 2 & 0 \\
\hline \multirow{3}{*}{5} & \multirow{3}{*}{150} & Líquens & 1 & 3 & 0 & 0 \\
\hline & & Briófitas & 0 & 0 & 0 & 0 \\
\hline & & Criptógamas vasculares & 2 & 0 & 2 & 2 \\
\hline 6 & 130 & Líquens & 0 & 0 & 0 & 2 \\
\hline
\end{tabular}

Cadernos de Pesquisa [ISSN 1677-5600]. Santa Cruz do Sul, v. 29, n. 2, p. 45-54, mai./ago. 2017

https://online.unisc.br/seer/index.php/cadpesquisa/index 


\begin{tabular}{|c|c|c|c|c|c|c|}
\hline \multirow[t]{2}{*}{ 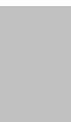 } & & Briófitas & 0 & 0 & 0 & 0 \\
\hline & & Criptógamas vasculares & 0 & 0 & 1 & 0 \\
\hline \multirow{3}{*}{7} & \multirow{3}{*}{170} & Líquens & 0 & 0 & 0 & 0 \\
\hline & & Briófitas & 0 & 0 & 0 & 0 \\
\hline & & Criptógamasvasculares & 6 & 6 & 6 & 6 \\
\hline \multirow{3}{*}{8} & \multirow{3}{*}{35} & Líquens & 0 & 3 & 1 & 3 \\
\hline & & Briófitas & 1 & 0 & 0 & 0 \\
\hline & & Criptógamas vasculares & 0 & 3 & 0 & 0 \\
\hline \multirow{3}{*}{9} & \multirow{3}{*}{53} & Líquens & 2 & 3 & 1 & 1 \\
\hline & & Briófitas & 1 & 3 & 3 & 3 \\
\hline & & Criptógamas vasculares & 0 & 0 & 0 & 0 \\
\hline \multirow{3}{*}{10} & \multirow{3}{*}{138} & Líquens & 3 & 3 & 0 & 0 \\
\hline & & Briófitas & 0 & 6 & 0 & 6 \\
\hline & & Criptógamas vasculares & 0 & 0 & 0 & 0 \\
\hline
\end{tabular}

Foram registrados 168 epífitas nos 10 forófitos analisados. 0 grupo mais representativo foram os Criptógamas vasculares, seguido por Briófitas e Líquens, representados por 62, 59 e 47 registros, respectivamente. No que se refere a distribuição vertical nos forófitos, $53,6 \%$ das epífitas registradas ocorreu no estrato até 2 metros, enquanto que 46,4\%, ocorreu acima de 2 metros. A preferência de distribuição geográfica foi maior na face Sul dos forófitos, perfazendo $53 \%$ dos registros, enquanto que na face Norte foram registrados $47 \%$ dos epífitos observados. Desta forma, a prevalência de ocorrência dos epífitos estudados teve maior acumulação na face Sul e estrato inferior dos forófitos, com 48 registros.

Quanto a dominância de epífitas, o maior número de registros de Criptógamas Vasculares foi verificado na Face Norte da metade superior dos forófitos, sendo verificados 20 espécimes. Esta preferência pode representar uma tendência dos espécimes deste grupo em buscar se desenvolver em ambiente mais próximo à copa dos forófitos, provavelmente, por conta das maiores taxas de luminosidade, independentemente das taxas de umidade e temperatura. Conforme Xavier e Barros (2003) as Criptógamas Vasculares são dependentes de condições ambientais para sua sobrevivência como temperaturas baixas, umidade relativa do ar elevada, e garoa noturna e matinal sempre presente. Estas características vão ao encontro da caracterização do clima regional, que, conforme Köppen e Geiger, para a região do município de Novo Cabrais, existe uma pluviosidade significativa ao longo do ano. Mesmo o mês mais seco, julho, a pluviosidade pode ser considerada alta, com média de $95 \mathrm{~mm}$ e pluviosidade média anual de $1420 \mathrm{~mm}$. O clima é classificado como Cfa com a temperatura média anual de $19.6^{\circ} \mathrm{C}$. Além disso, a maior ocorrência de ventos, seu principal agente dispersor de esporos, pode ser um fator determinante para sua ocorrência nos estratos mais elevados dos forófitos. No sentido de ocupação no estrato do forófito, os dados aqui levantados corroboram com o que descrevem Bittencourt, Corte e Sanquetta (2004), que verificaram uma prevalência de ocorrência de Criptogamas Vasculares em posições superiores a 7 metros. Estudos como os de Nieder et al. (2000), Kersten e Silva (2002), Breier, (2005), Kersten, Borgo e Silva (2009), relatam em seus estudos que as epífitas tiveram preferência pelas copas dos forófitos. Estes tipos de ambientes, copa, proporcionam maiores disponibilidades de luz para as epífitas (Gentry e Dodson, 1987; Benzing, 1990).

O grupo das Criptógamas Vasculares foi representado por dois gêneros da família Polypodiaceae, muito comuns na Mata Atlântica: Polypodium sp., que ocorre geralmente em locais recentemente alterados na floresta, em bordas de mata e na beira de estradas e trilhas, e Microgramma squamulosa, que ocorre no interior e na borda da floresta, sendo encontrada 
na Floresta Ombrófila Densa, Floresta Ombrófila Mista, Floresta Estacional Semidecidual e Formações Campestres (FLORASBS, 2014). Espécies do mesmo gênero são indicadas por Geraldino, Caxambú e Souza (2010) como espécies de grande importância em florestas secundária, referindo também a espécies Microgramma squamulosa como a mais frequente em copa de forófitos.

No que se refere a orientação geográfica de Criptógamas Vasculares, há uma preferência de ocorrência na face Norte dos Forófitos, perfazendo $56,5 \%$, em relação a face Sul, com 43,5\%.

O maior número de registros de Briófitas foi verificado na Face Sul da metade inferior dos forófitos, sendo verificados 17 espécimes. Conforme relata Silva e Porto (2007), em florestas úmidas a composição de briófitas difere com o tipo de substrato e com as condições microclimáticas. Ainda, Richards (1984) relata que algumas espécies ocorrem exclusivamente em ambientes sombrios e úmidos, enquanto outras são encontradas em ambientes secos e abertos. Os grupos observados têm a preferência por ambientes menos suscetíveis a variações climáticas mais bruscas por conta, principalmente do estresse hídrico das áreas mais próximas a borda. Esta afirmação corrobora com o que é referido por Gradstein (1997), onde o autor afirma que as espécies epífitas de Briófitas são consideradas de "sombra" e particularmente vulneráveis a distúrbios no ecossistema. Além disso, a formação de microambientes com microclimas na região Neotropical está associada a variações de temperatura, umidade e luminosidade (Gradstein et al., 2001), o que limitaria as áreas de ocorrência das Briófitas.

Os dados demonstraram uma tendência geográfica de as Briófitas ocorrerem, preferencialmente na face Sul dos Forófitos, perfazendo $54,3 \%$, em relação à face Norte, com $45,7 \%$. Esta prevalência pode estar relacionada com a incidência solar predominante no hemisfério norte, o que, consequentemente, possibilita um microclima mais úmido na face sul. Segundo o Sunearthtools, a prevalência solar nos pontos amostrados neste trabalho ocorre ao norte, sendo que as porções sul dos forófitos recebem menor incidência solar.

Os Líquens tiveram uma preferência por ocorrer na Face Sul da metade inferior dos forófitos, sendo verificados 17 espécimes. Os dados deste estudo corroboram com o que é verificado no estudo de Martins e Marcelli (2007), onde as autoras concluíram que as espécies ombrófilas têm a tendência de ocupar os níveis de até $40 \mathrm{~cm}$ no forófito, que foram as regiões mais sombreadas do tronco. No mesmo estudo, fica claro que espécies especialistas apresentam preferência por níveis de altura que podem estar relacionados com fatores microclimáticos como temperatura, luminosidade e umidade. Para Harris (1972), a distribuição vertical de liquens corticícolas em arbustos e carvalhos norte-americanos também estão relacionados aos fatores ambientais, como disponibilidade de água e a intensidade luminosa. Estes dados corroboram com os estudos de Marcelli $(1992 ; 1995)$ ao analisar a ecologia de líquens em mangues brasileiros.

Estudo de Santos (2012) conclui que a comparação entre as faces norte e sul, para o Brasil, sem considerar os ambientes mostra-se significativa tanto para as diferenças de abundância quanto para a cobertura de liquens, com as médias da face sul prevalecendo sobre as da face norte. A comparação da riqueza de liquens, em relação as faces do forófito, não é significativa, o que pode indicar que a orientação geográfica norte e sul não e é determinante para a diversidade de liquens. Para o autor, as diferenças encontradas entre as faces norte e sul dos troncos encontram-se principalmente no número e tamanho dos indivíduos e não na composição em espécies da comunidade liquênica.

As epífitas atuam nos processos e na manutenção dos ecossistemas, sua abundância e diversidade são influenciadas pela mudança nas condições ecológicas ao longo de gradientes ambientais. Além das características das árvores hospedeiras as quais contribuem para a estratificação vertical das epífitas no interior da floresta assim como o seu estabelecimento (Frenedozo et al., 2012).

Embora a dinâmica de populações epífitas seja pouco considerada em estudos científicos (Kersten, 2006), sabe-se que a densidade de seus indivíduos e espécies está 
inversamente correlacionada ao grau de alteração dos ecossistemas florestais (Bonnet e Queiroz, 2006).

Espécies tipicamente de sombra possuem limitações quanto a longos períodos de exposição ao sol, permanecendo quase que exclusivamente no sub-bosque das florestas, onde estas podem manter-se protegidas na sombra formada pelos indivíduos arbóreos (Oliveira, 2013). As formas de vida são adaptações às condições ecológicas específicas e demonstram as condições dos habitats, sendo relacionadas principalmente com a umidade do ambiente (Pócs, 1982). Formas de vida em tapetes possuem grande capacidade de retenção de água, crescendo muito aderidas à superfície do substrato (Glime, 2007), sendo abundantes em florestas com valores elevados de umidade e intensidade de luz, crescendo ao longo de todo o tronco da árvore (Oliveira, 2013), como foi observado na APA Morro de Osório onde a maioria das espécies apresentou crescimento em forma de tapete e ocuparam os três níveis estudados.

Na Tabela. 2 é possível observar as variações ambientais identificadas nos pontos de coleta. No estrato inferior dos forófitos, a média das temperaturas dos forófitos 1 ao 9 apresentam variação pouco significativa, no entanto no forófito 10 percebe-se uma temperatura baixa. Em estudo realizado no Jardim Botânico de Lajeado - RS (Souza et al., 2013) observaram que na base dos forófitos a temperatura é maior em relação aos demais pontos de coleta.

Tabela 2: Temperatura nos forófitos.

\begin{tabular}{|c|c|c|c|c|c|}
\hline \multirow[t]{2}{*}{ Forófitos } & \multirow{2}{*}{$\begin{array}{l}\text { Diâmetro } \\
\text { do forófito } \\
\text { (cm) }\end{array}$} & \multicolumn{2}{|c|}{$\begin{array}{c}\text { Temperatura } \\
\text { Metade Inferior do Tronco } \\
\text { (até } 2 \mathrm{~m} \text { ) } \\
\end{array}$} & \multicolumn{2}{|c|}{$\begin{array}{c}\text { Temperatura } \\
\text { Metade Superior do } \\
\text { Tronco (acima de } 2 \mathrm{~m} \text { ) } \\
\end{array}$} \\
\hline & & Face Norte & Face Sul & Face Norte & Face Sul \\
\hline 1 & 23 & 26,5 & 27,2 & 29,1 & 29,1 \\
\hline 2 & 14 & 30,3 & 30 & 30,3 & 30,3 \\
\hline 3 & 47 & 29,5 & 29,3 & 29,4 & 29,3 \\
\hline 4 & 110 & 29 & 28,4 & 29 & 28,2 \\
\hline 5 & 150 & 29,3 & 29,3 & 29,3 & 29,3 \\
\hline 6 & 130 & 29,3 & 29,3 & 29,2 & 29,3 \\
\hline 7 & 170 & 28,7 & 28,7 & 28,7 & 28,7 \\
\hline 8 & 35 & 27,9 & 27,9 & 27,9 & 27,8 \\
\hline 9 & 53 & 27,8 & 28 & 27,9 & 28,1 \\
\hline 10 & 138 & 19,4 & 19,2 & 29,4 & 29,1 \\
\hline
\end{tabular}

A umidade relativa do ar (Gráfico 1 ) teve como mínima 58ㄷ e máxima de 67으. $\mathrm{O}$ forófito um apresentou a umidade máxima registrada correspondente a 67으, isso ocorre provavelmente, em razão de estar próximo a um lago. Segundo Breier (2005) a umidade é um indicador importante para o adensamento das epífitas, justificando a abundância e diversidade deste grupo, encontradas neste forófito. 
Gráfico 1: Umidade relativa do ar verificada nos forófitos.

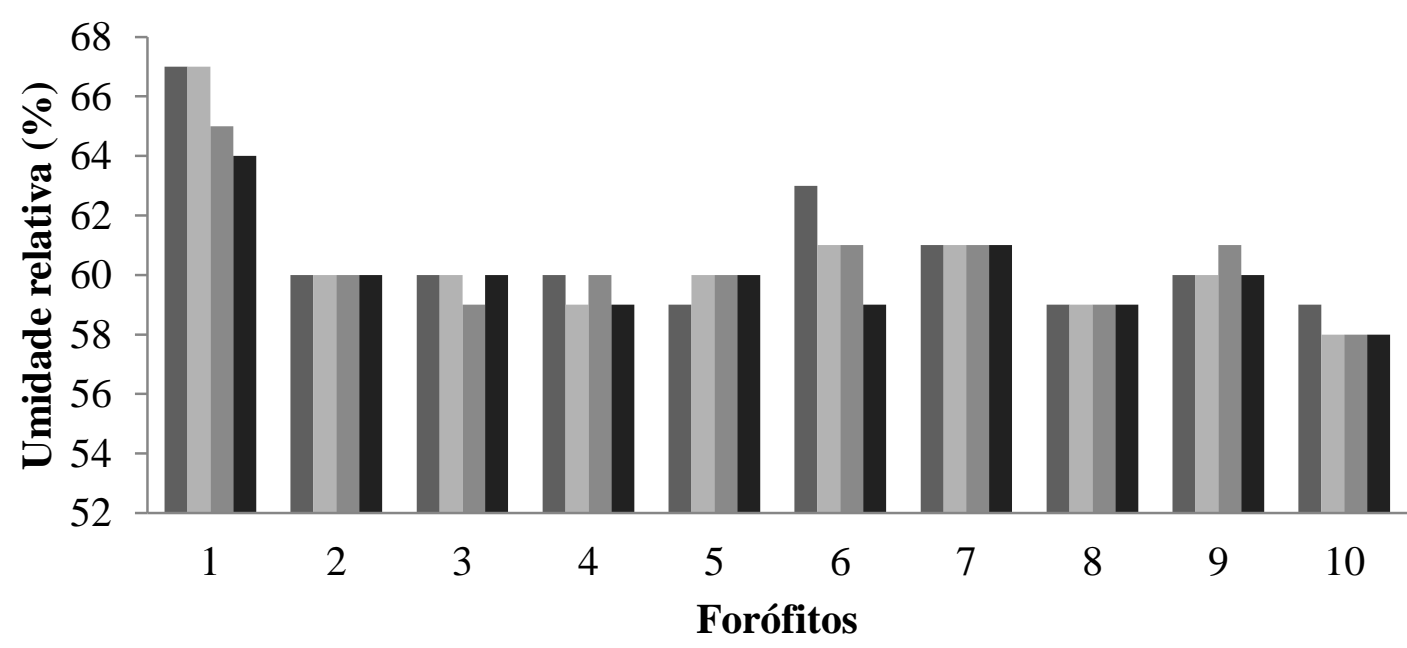

Umidade relativa $<2 \mathrm{~m}$ Face norte $\square$ Umidade relativa $<2 \mathrm{~m}$ Face sul

- Umidade relativa $>2 \mathrm{~m}$ Face norte $\boldsymbol{\|}$ Umidade relativa $>2 \mathrm{~m}$ Face sul

Em relação à riqueza, a área estudada apresenta um número baixo de espécies, principalmente se comparada com estudos de regiões da Floresta Atlântica, Floresta Ombrófila Mista e regiões costeiras do Brasil (Borgo e Silva, 2003; Giongo e Waechter, 2004; Gonçalves e Waechter, 2003; Kersten e Silva, 2001, 2002), todas com níveis de umidade relativamente maiores que a área estudada.

A maior umidade relativa do ar é observada no interior da floresta e decresce nas áreas abertas devido ao aumento da temperatura do ar e da velocidade do vento (Schulz, 1960; Lee, 1987). O chamado efeito de borda, que é responsável pela redução da umidade, é um fator limitante à comunidade epifítica (Bataghin et al., 2010).

\section{Considerações finais}

Fatores abióticos, como luminosidade, temperatura e umidade do ar exercem influência na diversidade e/ou abundância de epífitas. $\mathrm{Na}$ área de estudo não foram encontradas diferenças significativas na abundância e diversidade de epífitas sobre os forófitos analisados, quando relacionado com os fatores abióticos. $O$ pequeno número de espécies encontradas pode ser atribuído ao fato do trabalho se referir a um estudo de caso, com amostra sendo realizada em um único ponto amostral. Além disso, o ponto analisado apresenta características de borda de florestas em processo de regeneração. Mais estudos se fazem necessários nessas áreas, a fim de investigar os locais próximos deste fragmento com o objetivo de verificar se elas se tornam similares ao longo do tempo.

\section{Referências}

1. BENZING, D.H. Vascular epiphytes. Cambridge University Press, Cambridge. 1990.

2. BITTENCOURT, S.; CORTE, A. P. D.; SANQUETTA, C. R. Estrutura da Comunidade de Pteridophyta em uma Floresta Ombrófila Mista, Sul do Paraná, Brasil. Silva Lusitana, Lisboa, v. 12, n. 2, p. 243-254, dez. $2004 . \quad$ Disponível em $<$ http://www.scielo.mec.pt/scielo.php?script=sci_arttext\&pid=S0870$63522004000300008 \&$ Ing=pt\&nrm=iso>. Acessos em 23 jun. 2016. 
3. BONNET, A.; QUEIROZ, M. H. Estratificação vertical de bromélias epifíticas em diferentes estádios sucessionais da Floresta Ombrófila Densa, Ilha de Santa Catarina, Santa Catarina, Brasil. Revista Brasileira de Botânica, n. 29, p. 217-228. 2006.

4. BORGO, M.; SILVA, S. M. Epífitos vasculares em fragmentos de Floresta Ombrófila Mista, Curitiba, Paraná, Brasil. Revista Brasileira de Botânica, n. 26, v. 3, p. 391-401. 2003.

5. BREIER, T.B. O epifitismo vascular em florestas do Sudeste do Brasil. Tese de doutorado, Universidade Estadual de Campinas, Campinas, 2005. Disponível em: < http://www.bibliotecadigital.unicamp.br/document/?code=vtls000358758\&fd=y>

6. DISLICH, R.; MANTOVANI, W. A flora de epífitas da reserva da Cidade Universitária "Armando de Salles Oliveira" (São Paulo, Brasil). Boletim de Botânica da Universidade de São Paulo, n. 17, p. 61-83. 1998.

7. FloraSBS. Polypodiaceae. Disponível em: <https://sites.google.com/site/florasbs/polypodiaceae/>. Acesso em: 05 maio de 2016.

8. FRENEDOZO, R. C.; ARAÚJO, D. G.; CANCIÁN, M. A. E. Composição florística e efeito de borda antrópica na ocorrência de epífitas vasculares em fragmentos florestais na região leste da cidade de São Paulo, SP. Centro de Ciências Biológicas e da Saúde - Universidade Cruzeiro do Sul - São Paulo/SP. 2012.

9. GENTRY A.H.; DODSON, C.H. Diversity and biogeography of neotropical vascular epiphytes. Annals of the Missouri Botanical Garden, vol. 74, pag. 205-233. 1987.

10. GERALDINO, H.C.L.; CAXAMBÚ, M.G.; SOUZA, D.C. Composição florística e estrutura da comunidade de epífitas vasculares em uma área de ecótono em Campo Mourão, PR, Brasil. Acta Botanica Brasilica 21(2):469-482, 2010.

11. GIONGO, C.; WAECHTER, J. L. Composição florística e estrutura comunitária de epífitos vasculares em uma floresta de galeria Depressão Central do Rio Grande do Sul. Revista Brasileira de Botânica, n. 27, v. 3, p. 563-572. 2004.

12. GLIME, J.M. (2007). Bryophyte Ecology, Vol. 1. Physiological Ecology. Ebook sponsored by Michigan Technological University and the International Association of Bryologists.

13. GONÇALVES, C. N.; WAECHTER, J. L. Aspectos florísticos e ecológicos de epífitos vasculares sobre figueiras isoladas no norte da planície costeira do Rio grande do Sul. Acta Botânica Brasílica, vol. 17, pag. 89-100. 2003.

14. GRADSTEIN, S.R. The taxonomic diversity of epiphyllous bryophytes. Abstracta Botanica 21(1): 15-19, 1997.

15. GRADSTEIN, S.R.; CHURCHILL, S.P.; SALAZAR-ALLEN, N. Guide to the Bryophytes of Tropical America. Memoirs of the New York Botanical Garden 86: 1-577, 2001.

16. HARRIS, G. P. The Ecology of Corticolous Lichens. III. A Simulation Model of Productivity as a Function of Light Intensity and Water Availibility. J. Ecol. 60:19-40, 1972.

17. IBGE. Manual Técnico da Vegetação Brasileira. Rio de Janeiro, 2012. Disponível em: $<\mathrm{ftp}$ //geoftp.ibge.gov.br/documentos/recursos naturais/manuais tecnicos/manual tecn ico vegetacao brasileira.pdf $>$. Acesso em: 22 maio, 2016.

18. KERSTEN, R. A. Epifitismo vascular na bacia do Alto Iguaçu, Paraná. Tese de Doutorado, Universidade Federal do Paraná, Curitiba. 2006.

19. KERSTEN, R.A., BORGO, M.; SILVA, S.M. Diversity and distribution of vascular epiphytes in an insular Brazilian coastal forest. International Journal of Tropical Biology 57: 749-759, 2009.

20. KERSTEN, R. A.; SILVA, S. M. Composição florística e estrutura do componente epifítico vascular em floresta da planície litorânea na llha do Mel, Paraná, Brasil. Revista Brasileira de Botânica, n. 24, v. 2, p. 213-226. 2001.

21. KERSTEN, R. A.; SILVA, S. M. Florística e estrutura do componente epifítico vascular em floresta ombrófila mista aluvial do rio Barigüi, Paraná, Brasil. Revista Brasileira de Botânica, n. 25, v. 3, p. 259-267. 2002.

22. KERSTEN, R. A.; WAECHTER, H. L. Florística e estrutura de epífitos vasculares na transição entre as florestas ombrófilas densa e mista da vertente da Serra do Mar paranaense, 
Brasil. In: FELFILI, J. M.; EISENLOHR, P. V.; MELO, M. M. R. F.; ANDRADE, L. A.; MEIRA NETO, J. A. A. (Ed.). Fitossociologia no Brasil: métodos e estudos de casos. Viçosa: Ed. UFV, 2011. p. 479-503.

23. KRUSKAL, W.; WALLIS, W. A. Use of ranks in one-criterion variance analysis. Journal of the American Statistical Association, n. 47, v. 260, p. 583-621. 1952.

24. LEITE, P. F. As diferentes unidades fitoecológicas da Região Sul do Brasil - uma proposta de classificação. Curitiba: UFPR, p. 160. 1994.

25. MARCHIORI, J. N. C. Fitogeografia do Rio Grande do Sul: enfoque histórico e sistemas de classificação. Porto Alegre: EST, 2002.

26. MARCELLI, M.P. Ecologia Liquênica nos Manguezais do Sul-Sudeste Brasileiro. Bibliotheca Lichenologica, 47. J. CRAMER. Berlin. 310p., 1992.

27. MARCELLI, M.P. Habitat selection of epiphytic lichens on Rhizophora mangle in the mangroves of the Itanhaém river, São Paulo, Brazil. In Daniels, J.A., M. Schultz \& J. Peine (eds.) "Flechten Follmann, Contributions to Lichenology in Honour of Gerhard Follmann", p. 533-541. Geobotanical and Phytotaxonomical Study Group, Botanical Institute, University of Cologne, Cologne, 1995.

28. MARTINS, S. M. D. A.; MARCELLI, M. P. Distribuição vertical de liquens no tronco de Dodonaea viscosa L. na restinga de Itapuã, Rio Grande do Sul, Brasil. Revista Brasileira de Biociências, Porto Alegre, v. 5, supl. 2, p. 660-662, jul. 2007.

29. NIEDER, J., ENGWALD, S., KLAWUN, M.; BARTHLOTT, W. Spatial distribution of vascular epiphytes (inclusive hemiepiphytes) in a lowland Amazonian rain forest (Surumoni Crane Plot) in southern Venezuela. Biotropica, 32, 385-396, 2000.

30. OLIVEIRA H. S. Florística e ecologia de briófitas epífitas em fragmentos de Mata Atlântica no Estado da Bahia, Brasil. 2013. 156 f. Dissertação (Doutorado em Botânica) Universidade Estadual de Feira de Santana, Bahia. 2013.

31. PARQUE WITECK. Disponível em: <http://www.parquewiteck.com.br/>. Acesso em 22 mai. 2016.

32. PÓCS, T. 1982. Tropical Forest Bryophytes. In Bryophyte Ecology (A.J.E. Smith, ed.). Chapman and Hall, London, New York, p.59-103.PÓCS, T. 1996. Epiphyllous liverwort diversity at worldwide level and its threat and conservation. Anales Inst. Biol. Univ. Nac. Autón. México, Ser. Bot. 67(1):109-127.

33. RICHARDS, P.W. The Ecology of Tropical Forest Bryophytes. In: SCHUSTER, R.M. (Ed.). New Manual of Bryology. Nichinan: The Hattori Botanical Laboratory. p. 1233- 1270, 1984.

34. ROGALSKI, J. M.; ZANIN, E. M. Composição florística de epífitos vasculares no estreito de Augusto César, Floresta Estacional Decidual do Rio Uruguai, RS, Brasil. Revista Brasileira de Botânica, v. 26, p. 551-556. 2003.

35. SANTOS, J. M. G. D. Diversidade de liquens em leguminosas na Reserva Biológica de MogiGuaçu, SP / Janaína Maria Gonçalves dos Santos. - Botucatu; [s.n.], Tese (doutorado) 2012.

36. SILVA, M. P. P.; PORTO, K. C. Composição e riqueza de briófitas epíxilas em fragmentos florestais da Estação Ecológica de Murici, Alagoas. Revista Brasileira de Biociências, Porto Alegre, v. 5, supl. 2, p. 243-245, jul. 2007

37. SOUZA, A. H. C. et al. Distribuição espacial de epífitas sobre um forófito exótico e outro nativo na borda de uma trilha no Jardim Botânico de Lajeado, Rio Grande do Sul, Brasil. Destaques Acadêmicos, v. 05, n. 03, p. 163-172. 2013.

38. SUNEARTHTOOLS. Disponível em: < http://www.sunearthtools.com/dp/tools/pos_sun.php?lang=pt> Acesso em: 12 de setembro de 2016.

39. XAVIER, S. R. S.; BARROS, I. C. L. Pteridófitas ocorrentes em fragmentos de Floresta Serrana no Estado de Pernambuco, Brasil. Rodriguésia, 53: 13-21, 2003. 